\title{
LAS PINTURAS MURALES DEL PALACIO DE LOS MARQUESES DE QUINTANAR EN SEGOVIA
}

Data recepción: 2010/06/17

Data aceptación: 2011/06/30

Contacto autora: luciagomezrobles@gmail.com
Lucía Gómez Robles

Universidad de Jaén

RESUMEN

Con motivo de la restauración del palacio de los marqueses de Quintanar en Segovia se ha realizado el estudio histórico de las decoraciones del inmueble que han arrojado interesantes conclusiones. Una de estas decoraciones son las pinturas murales de una de las salas, de finales del siglo XVIII. La particularidad de estas decoraciones consiste en una influencia inglesa, del estilo Adam de moda en aquel tiempo en el Reino Unido, poco conocida hasta el momento.

Palabras clave: Quintanar, Segovia, Robert Adam, pintura mural

\section{ABSTRACT}

In conjunction with the restoration of the palace of the marquesses of Quintanar in Segovia, a historical study of the building's decor has been carried out, a study that has yielded some interesting conclusions. One of the rooms is decorated with late-18th century murals with a hitherto little-known British influence, painted as they are in the Adam style, which was in vogue in Great Britain at that time.

Keywords: Quintanar, Segovia, Robert Adam, mural painting

El palacio de Quintanar, en la calle San Agustín de Segovia, es un edificio de finales del siglo XV y principios del siglo XVI que ha sufrido numerosas reestructuraciones e incluye entre sus numerosas capas decorativas algunas de especial interés. A mediados del siglo XX dejó de pertenecer a la familia y pasó a convertirse en un edificio público.

Durante un tiempo ha sido utilizado, entre otras actividades, para la Beca de Pintura de Pensionados de Segovia, organizada por la Real Academia de Historia y Arte de San Quirce.

En 2007 la Consejería de Cultura y Turismo de la Junta de Castilla y León aprobó un presupuesto para rehabilitar el edificio para albergar la sede del Centro de Artes Audiovisuales y Tratamiento de Nuevas imágenes y la Universidad de Verano. En el transcurso del estudio histórico artístico sobre las decoraciones interiores del palacio se ha realizado un estudio histórico de las pinturas al temple de una de las salas con una curiosa vinculación con el mundo inglés. Se describen a continuación las características y peculiaridades de dichas pinturas.

\section{Las pinturas "pompeyanas" del palacio de Quintanar}

De todas las decoraciones presentes en el palacio de Quintanar se pueden destacar especialmente dos, los papeles pintados y las pinturas murales de una de las salas (Fig. 1). Se trata de una decoración de motivos clásicos o también llamados "pompeyanos", debido a que se realizaron a finales del siglo XVIII, en un momento de gran influencia de los descubrimientos de Pompeya y Herculano sobre los motivos decorativos realizados en toda Europa.

Esta sala se encuentra decorada en tres de sus cuatro paredes con unas pinturas al temple 
de iconografía clásica, como ya se ha mencionado, que se encuentran muy deteriorados por un picado sistemático realizado sobre toda la superficie de las paredes a excepción del zócalo.

Estas pinturas se estructuran en tres bandas verticales que repiten el esquema decorativo con pequeñas variaciones en algunos detalles.

El esquema de cada banda, a su vez, se divide en un zócalo en dos partes, la inferior lisa sin dibujo y la superior blanca con dos motivos vegetales decorativos distintos, uno en la mayor parte de la habitación y el otro en una esquina de la misma, sin que exista motivo aparente para este cambio.

La parte superior se compone de un friso de motivos vegetales repetitivos: un ramo de flores rodeado de una guirnalda sin flores. A ambos lados se sitúa un lazo del que pende otro motivo vegetal.

La parte central y principal se divide a su vez en dos, la inferior, de formato vertical y mayor tamaño y la superior, horizontal. Ambas se encuentran enmarcadas y con relieve fingido. Se separan de la banda siguiente por un pilar también fingido que en sus bordes presenta una cenefa realizada con un motivo repetido de tipo palmeta.

El dibujo de la parte central es una composición de las llamadas "de grutescos", que incluye abundantes motivos vegetales, roleos, jarrones y seres bimórficos.

En el dibujo superior dos figuras femeninas flanquean un tondo que contiene una urna, con motivos vegetales a los lados.

\section{Los grutescos}

Posiblemente uno de los motivos más interesantes de la composición son los grutescos. Define la RAE los grutescos como "el adorno caprichoso de bichos, sabandijas, quimeras y follajes". Reciben este nombre por haber sido descubiertos en el renacimiento al desenterrar parte de la Domus Aurea neroniana. Se trataba de elementos decorativos fantasiosos que combinaban adornos vegetales, figuras animales y antropomórficas, a menudo en forma híbrida, y piezas arquitectónicas y de orfebrería.

Desde su descubrimiento en el siglo XV han sido utilizados por los artistas de todas las épo- cas en los diseños decorativos, primero, durante el renacimiento, basándose en los restos romanos conocidos en aquel momento, especialmente de la Domus Aurea, y posteriormente mirando también a todos los estilos anteriores que previamente los habían utilizado.

En el siglo XV todavía se mezclarán los elementos clásicos con algunos provenientes del Medievo que habían permanecido desvirtuados en la memoria artística colectiva y en los momentos posteriores el uso de estos grutescos se fue adaptando al gusto de la época.

A comienzos del siglo XVIII los grutescos se habían integrado perfectamente en el sistema iconográfico del rococó y los modelos que se utilizaban en ese momento eran los repertorios realizados en el siglo anterior. Pero el clima artístico se modificó en la segunda mitad de la centuria lo que, ayudado por los descubrimientos de Herculano en 1738 y Pompeya en 1748, y la posterior publicación de las excavaciones en 1757 y 1792 respectivamente, inició una nueva época de sobriedad.

Los grutescos del neoclasicismo, sin embargo, no tendrán exclusivamente como modelo los restos clásicos, sino que incorporarán parte de las aportaciones del siglo XVI, en especial las de Rafael, dentro de su repertorio decorativo. Se volverán, además, más ligeros dando más espacio al fondo que será predominantemente blanco.

En el diseño de interiores, uno de los estilos con nombre propio de este momento será el "Adam's style" o estilo Adam, desarrollado por los hermanos Adam y en especial por Robert Adam. Tuvo gran influencia en Inglaterra, pero también alcanzó a los Estados Unidos, Francia e incluso Rusia.

\section{Análisis de los frescos de la sala de las pinturas}

Las pinturas de la sala de Quintanar coinciden con este momento artístico y pueden datarse a finales del siglo XVIII. Pero su interés radica en que aparecen entre los motivos de los dibujos algunos elementos propios de los diseños de Robert Adam, que son en parte publicados entonces bajo el título Works in Architecture of Robert and James Adam entre 1773 y 1779, volúmenes 1 y 2 (ADAM, 1980). 


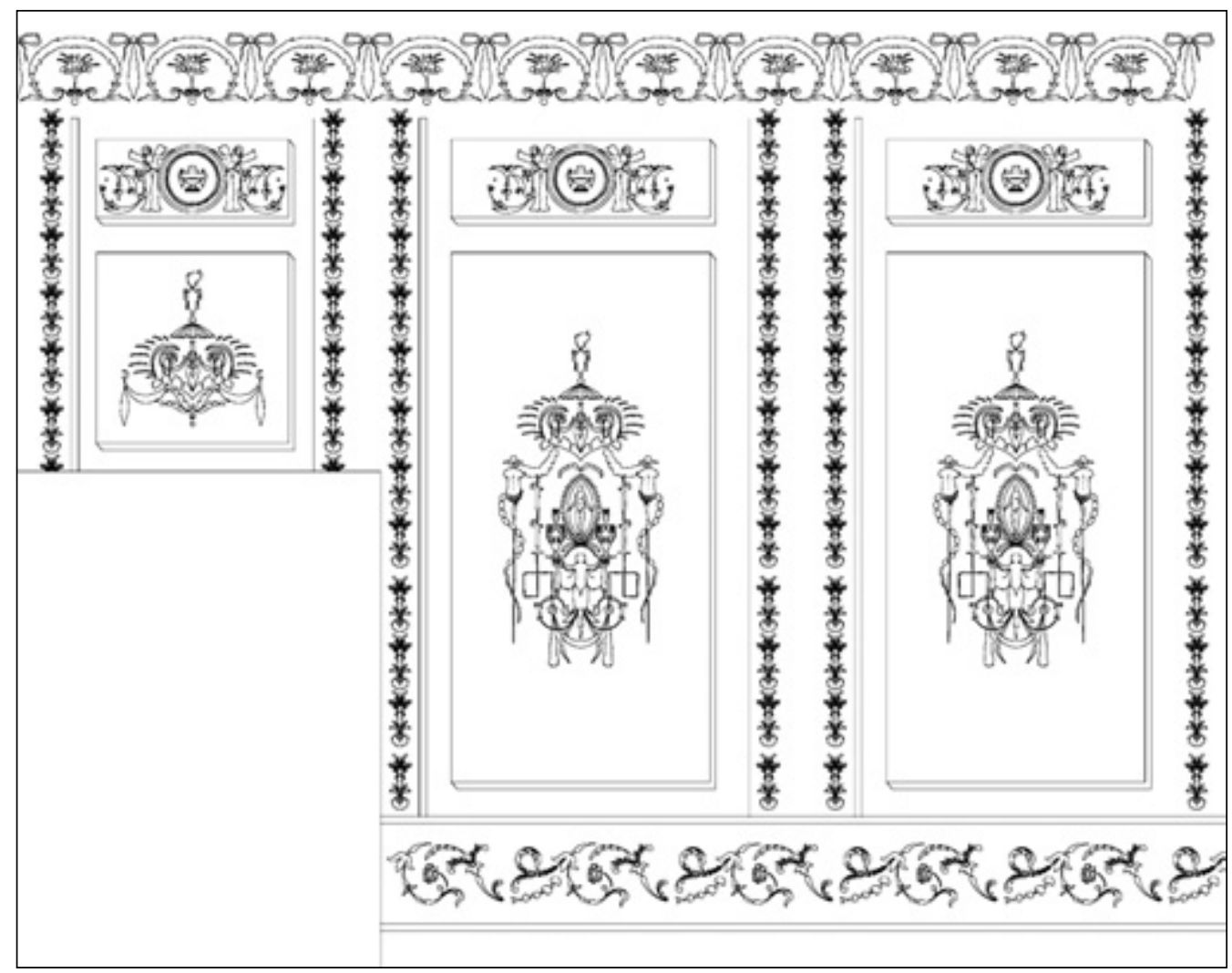

Fig. 1. Esquema decorativo de una de las paredes de la sala de las pinturas.

El libro de Adam fue una de las más influyentes e innovadoras colecciones de diseños de edificios y para interiores de su momento, pero hasta ahora no se habían encontrado muestras de su influencia en España. Adam se inspiró en las numerosas publicaciones sobre los restos romanos encontrados en la época, así como sus propios apuntes realizados durante el Grand Tour, bajo la tutela de Piranesi. Los vasos griegos, los grutescos de las pinturas murales romanas y las decoraciones de Rafael y Giulio Romano en la Loggia vaticana y las villas Madama y Pamphili fueron los motivos de partida de Adam para crear sus propios motivos a partir de aquellos.
Estas decoraciones consistían en medallones y paneles rectangulares interconectados con motivos clásicos (BUATTA, 2006: 142-152).

Los elementos de las obras de Adam identificados en Segovia son los siguientes (ver anexo 1): el friso superior de la sala etrusca de Osterley Park, que es prácticamente el mismo que el de Quintanar; los frisos decorativos del techo de la Wynn House y de la Derby House, que se asemejan a uno de los diseños vegetales del zócaIo; el personaje bimórfico de Osterley Park, muy parecido al segoviano; y por último el tondo flanqueado por esfinges del diseño para la chimenea de la Derby House, en Londres. 
Los motivos no son idénticos, sin embargo el parecido es suficiente como para afirmar que el artista de Segovia debió conocer el trabajo de Adam. En el caso del friso superior la posición y la escala es la misma, al igual que la composición: una cesta con flores en el caso del diseño de Adam que en Quintanar se convierte en un ramo de flores, rodeado por una guirnalda semicircular, separadas entre sí por un elemento vegetal vertical que parte de un lazo. En el caso de Adam los extremos de los lazos se unen a la cesta central, mientras que en Quintanar quedan sueltos.

El motivo del zócalo tiene menor parecido al de la Wynn House pero aún así mantiene una composición significativamente similar: ambas conforman círculos mediante motivos vegetales que disminuyen progresivamente de tamaño. Dichos círculos se separan por dos nuevos vástagos vegetales. La diferencia entre los diseños de Adam y Quintanar está en el dibujo contenido en el interior de las estructuras circulares: mientras que Adam incluye un medallón en el centro de un rombo de lados curvos, en Quintanar aparece una flor enmarcada por dos nuevos elementos vegetales.

Si se analiza gráficamente la composición observamos que la estructura es la misma, y únicamente modifica determinados elementos (Fig. 2).

En el friso de la Derby House, también similar al mismo motivo, los círculos vegetales sí encierran una flor del mismo modo que en Quintanar.

El siguiente elemento relacionado con los diseños de Robert Adam para Osterley Park es la figura bimórfica (mitad hombre, mitad planta) del centro de la composición central. Existen multitud de composiciones de este tipo a lo largo de la historia del arte, pero hay una significativa relación entre ambos dibujos. La posición de la parte antropomórfica es la misma, de frente y con los brazos abiertos, ambos de hombre adulto; la parte inferior vegetal tiene una composición muy similar en ambos diseños, ambos se abren de forma simétrica y a los lados se desarrollan sendos roleos. Teniendo en cuenta además que, gracias al friso, sabemos que el autor de Quintanar tuvo acceso a este diseño, no es de extrañar que también utilizara esta figura en su propio dibujo.

Por último, también existe un diseño de Robert Adam para una chimenea de la Dervy
House que contiene un tondo con una urna muy similar a la de los tondos de Quintanar, en el caso londinense, sin embargo, está flanqueado por esfinges.

Dadas las similitudes se puede aceptar que el artista de Quintanar debió conocer la obra de Adam y, aunque en principio el modo más sencillo hubiese sido a través de la publicación, la aparición de motivos decorativos procedentes de Osterley Park, obliga a pensar que quien realizó el diseño tuvo contacto con las obras arquitectónicas o el propio estudio de Robert Adam, es decir, un diseñador inglés o un artista español que visitara Inglaterra.

Tanto la Wynn House como la Derby House fueron publicadas en el segundo volumen de The Works in Architecture of Robert and James Adams en el año 1779, sin embargo, Osterley Park no apareció en ninguna de las dos primeras publicaciones, ni en la tercera, póstuma, de 1822. De hecho no aparecen publicaciones que contengan los diseños de la habitación etrusca de Osterley Park hasta el tercer cuarto del siglo XIX, cuando Adam volvió a ponerse de moda.

El pintor de Quintanar, por tanto, debió conocer la obra de Adam, y haber tomado apuntes de los motivos decorativos, en algún momento, que le permitiera hacer una nueva composición basada en ellos.

A finales del siglo XVIII hubo movimiento de artistas ingleses en España (GÓMEZ, 2008: 133145), como el arquitecto James Canavah Murphy (1760-1814), así como españoles que viajaron a Inglaterra como Antonio Ponz que escribió en 1785 el "Viaje fuera de España" en dos volúmenes, incluyendo los Países Bajos, Holanda, Bélgica, Francia e Inglaterra. Y también llegaron a España algunas publicaciones inglesas como el libro de Adam Ruins of the palace of the Emperor Diocletian at Spalatro in Dalmatia, impreso en Londres en 1764, que figuraba entre las publicaciones disponibles en la biblioteca de la Real Academia de San Fernando, en el inventario realizado en 1828, "Índice de las obras que posee la biblioteca de la real academia de nobles artes de san Fernando, 1828" (PAYNE, 2004: 116).

En cualquier caso, el pintor de Quintanar debió conocer la obra de Adam en una fecha no anterior a 1775-1776 y realizar los dibujos del 

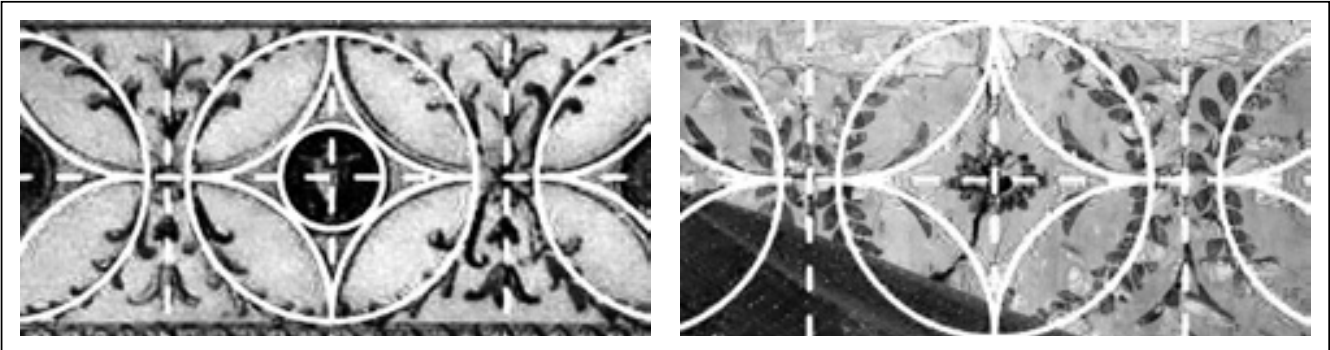

Fig. 2. Composición de Robert Adam (izq.) y composición de Quintanar de uno de los motivos vegetales del zócalo (der.).

palacio segoviano en algún momento del último cuarto del siglo XVIII ya que hacia 1816 el edificio, y la habitación de las pinturas en concreto, fueron redecorados con los papeles pintados procedentes de Francia.

Estas dos intervenciones tan importantes en la historia decorativa del edificio se suceden en un corto espacio de tiempo, revelando, probablemente, un buen momento económico de la familia y una importante fascinación por las modas contemporáneas.

Ver listado de elementos relacionados con Adam y el dibujo de referencia (Anexo 1).

\section{Conclusiones}

Al comienzo del estudio de las decoraciones del palacio de los marqueses de Quintanar se desconocía, no sólo la datación, sino el valor de las mismas, ya que pasaban desapercibidas, confundidas en la multitud de capas decorativas.

Del análisis realizado se extrae que existe una relación entre las pinturas neoclásicas de Segovia y los diseños de ese momento realizados por el arquitecto Robert Adam en el Reino Unido, lo que demuestra una transmisión de esta moda decorativa europea a finales del siglo XVIII que hasta el momento no se había contemplado en lo que respecta a España.

Por tanto, y mientras aparecen nuevos ejemplos desconocidos de otros testimonios de influencias de las modas británicas, y muy concretamente de los hermanos Adam, de finales del XVIII en España, Quintanar constituirá un ejemplo fundamental y de inestimable interés para la historiografía de las artes decorativas de finales del siglo XVIII en nuestro país.

\section{Agradecimientos}

Quiero agradecer a Sagrario Abelleira Méndez y a María Suárez-Inclán la oportunidad de realizar esta investigación, a Olga Muñoz Navarro, Coordinadora de las Bibliotecas Municipales de Cuenca y a Stephen Astley, conservador de los dibujos del Museo Sir John Soane por su colaboración en la búsqueda de la primera publicación de la habitación etrusca y a la Dra. Victoria Quirosa García por sus sugerencias y su apoyo. 
Las pinturas murales del palacio de los marqueses de Quintanar en Segovia

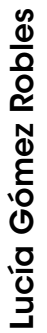

Anexo 1. Elementos relacionados con Adam y dibujo de referencia.

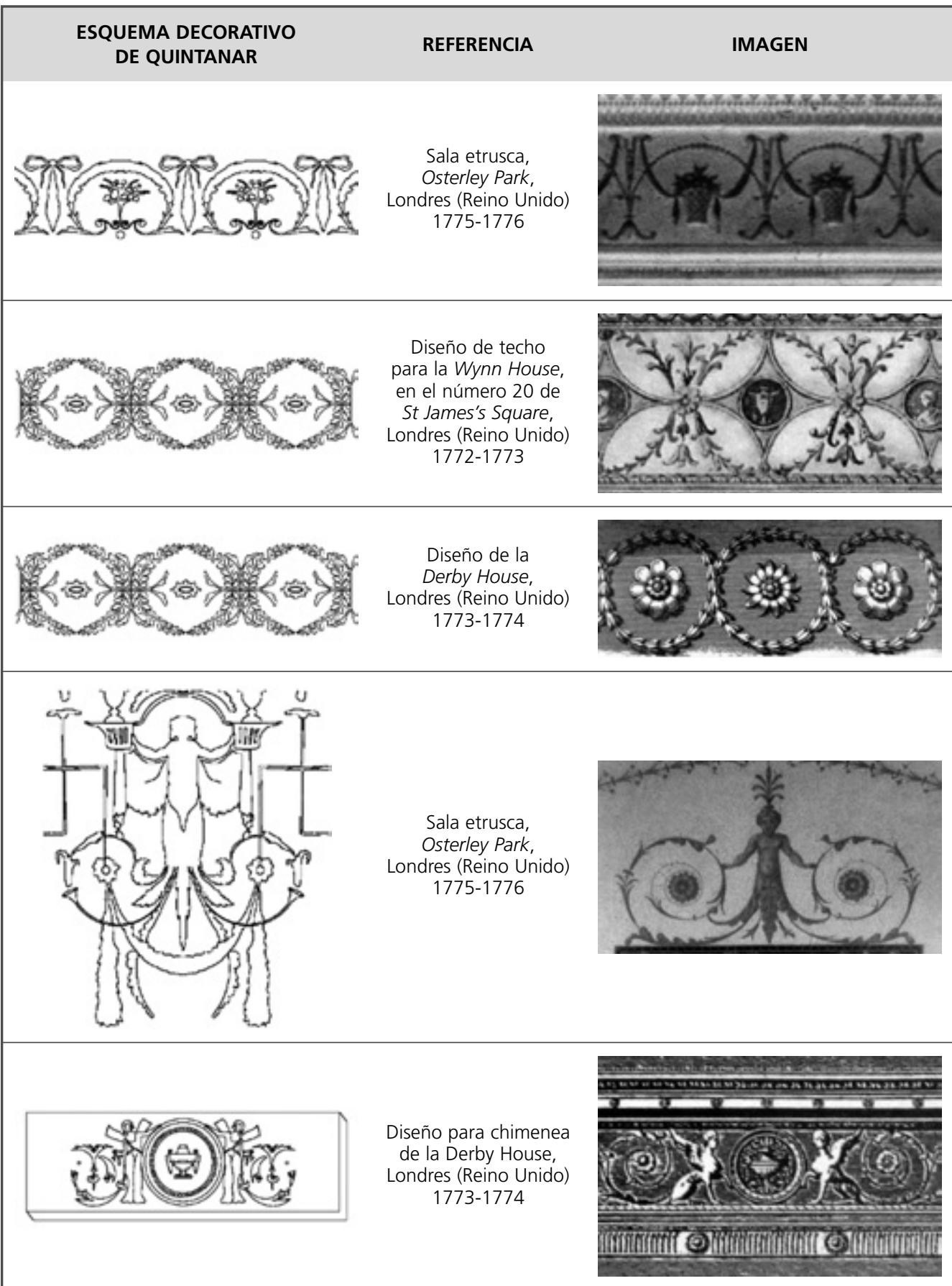




\section{BIBLIOGRAFÍA}

ADAM, Robert y James. The Works in Architecture of Robert and James Adam. Ed. Dover Publications, Inc. New York, 1980.

BUATTA, Mario. Classic English design and antiques: period styles and furniture. The Hyde Park Antiques collection. Ed. Rizzoli. New York, 2006.

GÓMEZ ROBLES, LUCía, FERNÁNDEZ RUÍZ, José Antonio y TORICES ABARCA, Nicolás. Tourist in Granada.
La ciudad de 1830 vista por los viajeros. Ed. Fundación Albaicín. Granada, 2008.

PAYNE, Christiana y VAUGHAN, William. English accents: interactions with British art, c. 1776-1855. Ed. Ashgate Publishing Limited, 2004. 